\title{
DRB1 as a mediator between transcription and microRNA processing
}

2 Dawid Bielewicz*, Jakub Dolata, Mateusz Bajczyk, Lukasz Szewc, Tomasz Gulanicz, Susheel

3 Sagar Bhat, Anna Karlik, Artur Jarmolowski and Zofia Szweykowska-Kulinska

Department of Gene Expression, Institute of Molecular Biology and Biotechnology, Faculty of Biology, Adam Mickiewicz University, Poznan, Poland

*Corresponding author: bieda@amu.edu.pl

\section{Abstract}

DRB1 (HYL1) is a double-stranded RNA binding protein involved in miRNA processing in plants. It is a core component of the Microprocessor complex and enhances the efficiency and precision of miRNA processing by DCL1 protein. In this work, we report a novel function of DRB1 protein in the transcription of MIR genes. DRB1 co-localizes with RNA Polymerase II and affects its distribution along MIR genes. Moreover, proteomic experiments revealed that DRB1 protein interacts with many transcription factors. Finally, we show that the action of DRB1 is not limited to MIR genes as it impacts expression of many other genes, majority of which are involved in plant response to light. These discoveries add DRB1 as another player of gene regulation at transcriptional level, independent of its role in miRNA biogenesis.

\section{Key words}

DRB1, HYL1, Microprocessor, microRNA, transcription, RNA Pol II

\section{Introduction}

MicroRNAs (miRNAs) are small $\sim 21$ nt RNA molecules that play vital role in post-transcriptional regulation of gene expression (Bartel 2004). miRNAs are involved in a vast range of metabolic processes and hence act as regulatory molecules in overall plant development, for example in processes like determination of leaf shape, flowering time and response to environmental conditions (Palatnik, Allen et al. 2003, Chen 2004, Kruszka, Pieczynski et al. 2012, Barciszewska-Pacak, Milanowska et al. 2015). miRNA genes (MIR) are transcribed by RNA Pol II (Xie, Allen et al. 2005) and the primary transcripts (known as primary-miRNAs; pri-miRNAs) contain a stem-loop region. The pri-miRNAs are then cleaved to release mature miRNAs by a complex of enzymes known as the Microprocessor. Notably, the stem-loop region of primiRNAs serves as a mark for the Microprocessor to recognize and start processing the primiRNAs (Kurihara and Watanabe 2004, Dolata, Taube et al. 2018). Microprocessor is 
a complex of three core proteins, Dicer Like 1 (DCL1), Double-stranded RNA Binding protein 1 (DRB1) (also known as Hyponastic Leaves 1 (HYL1)) and Serrate (SE) (Yang, Liu et al. 2006, Fang and Spector 2007, Dong, Han et al. 2008, Dolata, Taube et al. 2018). DCL1 is a RNAse III type enzyme that cuts and releases miRNA/miRNA* from pri-miRNAs in a two-step reaction (Park, Li et al. 2002, Reinhart, Weinstein et al. 2002). DRB1 and SE assist and increase the accuracy of pri-miRNA cleavage by DCL1 (Kurihara, Takashi et al. 2006). All three of these core components are necessary for proper functioning of Microprocessor and in mutants of any of these proteins, pri-miRNAs accumulate and mature miRNAs are downregulated (Laubinger, Sachsenberg et al. 2008, Szarzynska, Sobkowiak et al. 2009, Zielezinski, Dolata et al. 2015). Two modes of Microprocessor mediated pri-miRNA cleavage have been described: base to loop (first cut at the base, second closer to the loop structure) and loop to base (first cut in the loop and second closer to the base), depending on the directionality of DCL1 cleavage (Kurihara and Watanabe 2004, Bologna, Mateos et al. 2009).

DRB1, a double stranded RNA binding protein, contains two double stranded RNA binding domains (dsRBDs) in its N-terminal region followed by a nuclear localization signal (NLS) and an unstructured C-terminal region (Yang, Chen et al. 2010). DRB1 is considered to form a homodimer and bind the miRNA/miRNA* duplex region of pri-miRNA (Burdisso, Milia et al. 2014, Yang, Ren et al. 2014). DRB1 knockout has a pleiotropic impact on the phenotype of plants (among the others defects in leaf shape and late flowering time) and their response to auxin and ABA (Lu and Fedoroff 2000, Vazquez, Gasciolli et al. 2004). So far, no ortholog of DRB1 has been identified in mammalian cells. However, similar to plants, mammalian RNA nucleases (Drosha and Dicer) also require proteins containing dsRBDs: DiGeorge syndrome critical region 8 (DGCR8) and transactivation response element RNA-binding protein (TRPB), for proper functioning (Han, Lee et al. 2004, Chendrimada, Gregory et al. 2005, Haase, Jaskiewicz et al. 2005). Both, DRB1 and DGCR8 are nuclear proteins involved in first step of pri-miRNA maturation i.e. cleavage by RNAse III (Gregory, Yan et al. 2004). However, like TRBP, DRB1 can be phosphorylated which affects its activity (Paroo, Ye et al. 2009, Manavella, Hagmann et al. 2012, Achkar, Cho et al. 2018).

miRNA production in mammalian cells is co-transcriptional as Drosha and DGCR8 have been shown to bind regions in the proximity of many gene promoters (not just MIR genes) and consequently Drosha knockdown in HeLa cells negatively impacts gene transcription (Gromak, Dienstbier et al. 2013). Similarly, in plants, co-transcriptional processing of plant pri-miRNAs 
has been proposed through the association of DCL1 with the chromatin and Elongator complex (Fang, Cui et al. 2015). However, presence of pri-miRNA transcripts is necessary for the association of DCL1 with chromatin. Since the interaction between DCL1 and DRB1 has been established, here we ask whether it possible that DRB1 is also involved in the transcription of MIR genes?

\section{Results}

\section{DRB1 is a positive regulator of MIR gene transcription.}

To investigate the possibility that DRB1 protein is involved in the transcription of MIR genes we used a GUS reporter line system. We independently crossed two reporter lines with GUS under two different MIR gene promoters (pMIR393A:GUS and pMIR393B:GUS (Parry, Calderon-Villalobos et al. 2009)) in the wild type (Col-0) background with hyl1-2 mutants (DRB1 knockout mutants). We observed that the expression of GUS protein driven by MIR gene promoter was remarkably lower in hyl1-2 background as compared to Col-0 (Fig. 1A). We measured the level of GUS transcripts in pMIR393A:GUS, pMIR393B:GUS, pMIR392A:GUSxhyl1-2, and pMIR392B:GUSxhyl1-2 reporter lines using RT-qPCR and observed a significant decrease in the level of GUS transcripts in PMIR392A:GUSxhyl1-2, and pMIR392B:GUSxhyl1-2 plants. Additionally, we also tested the levels of pri-miRNA393A and pri-miRNA393B in the obtained lines and as expected, these pri-miRNAs were upregulated in the hyl1-2 mutant background (Fig. 1B). These data indicate that DRB1 which is involved in pri-miRNA processing may also regulate the transcription of $M I R$ genes. However, it is also possible that the strong downregulation of GUS expression in the hyl1-2 background is caused by a feedback mechanism in which the global downregulation of miRNAs in hyl1-2 results in an upregulation of a yet unidentified transcriptional factor(s) that in turn inhibits MIR393A and MIR393B transcription. To address this question, we decided to restore the miRNA levels in the reporter lines within hyl1-2 background. For this purpose we crossed these lines with a DCL1 mutant: $d c / 1-13$ (Tagami, Motose et al. 2009). $d c / 1-13$ mutant has a point mutation in the $D C L 1$ gene which promotes DCL1 activity in absence of DRB1. The point mutation in DCL1 gene results in an amino acid substitution of Glu to Lys in the ATPase/DExH-box RNA helicase domain. Hence, the expression of $d c / 1-13$ allele in the $h y / 1-2$ background restores the level of miRNAs and rescues plants from the developmental abnormalities associated with lower level of miRNAs. We prepared a hyl1-2/dcl1-13 transgenic line carrying genomic sequence of 
mutated $D C L 1$ gene under its native promoter. We obtained four independent transgenic lines and confirmed previous results showing that the expression of $d c / 1-13$ allele restores the levels of pri-miRNAs and mature miRNAs in hyl1-2 background (Fig. S1). We then crossed our reporter lines with hyl1-2/dc/1-13 transgenic plants. Analysis of GUS staining in the offspring clearly showed that GUS protein is still inefficiently expressed in the hyl1-2/dcl1-13 mutant background (FIG. 1A, right panel). Additionally, we also performed RT-qPCR analysis to measure the GUS transcript level and like in hyl1-2 mutant, in hyl1-2/dc/1-13 mutant plants, GUS transcript was downregulated in comparison to wild type plants (FIG. 1B, right panel). Hence, our data shows that DRB1 is a direct positive regulator of MIR gene transcription.

\section{DRB1 colocalizes with RNA polymerase II}

The observation that DRB1 is required for a proper transcription of MIR393A and MIR393B prompted us to test the stage at which it affects transcription. We tested the co-localization of DRB1 with RNA Pol II at different stages of transcription. We performed immunolocalization in fixed nuclei from wild type plants and observed strong colocalization of DRB1 and total RNA Pol II (Fig. 2). We used antibodies specific for Serine5 (transcription initiation) and Serine2 (transcription elongation) of RNA Pol II C-terminal domain (CTD) independently to further characterize the nature of these interactions. The results showed that DRB1 is associated with RNA Pol II already at the transcription initiation stage (Ser5) and remains associated with RNA Pol II during the elongation step (Ser2). Since DRB1 is a part of Microprocessor core complex we considered the possibility that DRB1 is brought to RNA Pol II by another member of Microprocessor. Recently it was shown that SE is directly associated with specific regions of Arabidopsis chromatin (Speth, Szabo et al. 2018). Apart from its role in miRNA biogenesis, SE is involved in many processes connected with RNA metabolism like splicing, 3'-end formation, RNA transport and RNA stability (Laubinger, Sachsenberg et al. 2008, Raczynska, Stepien et al. 2014). To exclude the possibility of SE mediating DRB1 and RNA Pol II co-localization, we investigated the interaction of DRB1 with RNA Pol II in the se-2 mutant plants. (Fig S2). Similar to our previous experiment, these results were also obtained for total RNA Pol II and for RNA Pol II phosphorylated at Ser5 or Ser2. We did not see any decrease in co-localization of DRB1 and RNA Pol II in the absence of SE, thus showing that the association of DRB1 with RNA pol II is not SE dependent. We also addressed the question whether DRB1 is involved throughout the whole process of transcription. For this purpose, we performed immunolocalization 
studies for DRB1 and RNA Pol II using antibodies against DRB1 and antibodies which recognize RNA Pol II phosphorylated at threonine 4 (Thr4) of its CTD domain (mostly associated with transcription termination or 3' end processing events) (Hintermair, Heidemann et al. 2012, Nojima, Rebelo et al. 2018). Our co-localization results showed that DRB1 did not co-localize with RNA pol II phosphorylated at Thr4 in either wild-type or se-2 mutant plants. These data show that DRB1 is involved in transcription process from initiation to elongation, but not at the termination stage and DRB1's role in transcription stimulation is not mediated by other proteins, at least not by SE.

\section{DRB1 protein interacts with transcription factors}

Since we found that DRB1 acts as a positive regulator of MIR gene transcription and colocalizes with RNA Pol II we decided to test whether it also interacts with other known transcription factors. For this experiment, we used a transgenic line containing DRB1 tagged with HA epitope ( $p D R B 1: D R B 1: H A)$ and anti-HA antibodies to co-immunoprecipitate with its potential protein interactors which were later identified by Mass Spectrometry analysis. As a benchmark for our experiment, we searched for previously published data regarding DRB1 interactors and compared with our data. We were able to identify bona fide DRB1 partners KETCH1 and CDC5 in our data (Fig 3). (Zhang, Xie et al. 2013, Zhang, Guo et al. 2017). KETCH1 is a karyopherin enabling the transport of DRB1 to nucleus and CDC5 is a MYBtranscription factor. Interestingly CDC5 was showed to be involved in the transcription of $M I R$ genes (Zhang, Xie et al. 2013). Similar to DRB1 mutant plants, in the CDC5 knockout mutant the GUS reporter which was under the control of MIR gene promoter was downregulated. However, $c d c 5$ mutants showed no enrichment in pri-miRNA level, which can be explained that CDC5 is involved in transcription of MIR genes but not in the processing of pri-miRNA like DRB1 (Vazquez, Gasciolli et al. 2004, Zhang, Xie et al. 2013). Interestingly, in our co-IP results we found that DRB1 was associated also with transcription factors from the Topless transcription factor family (Fig 3). However, the interaction between Topless transcription factors and DRB1 requires more detailed investigation.

\section{Distribution of RNA polymerase II is affected in hyl1-2 mutant}

In light of our data showing that DRB1 and RNA Pol II co-localize, we tested whether this colocalization also affects RNA Pol II occupancy on MIR genes. For this purpose, we performed Chromatin Immunoprecipitation (ChIP) using antibody against total RNA Pol II followed by 
qPCR in wild-type and hyl1-2 mutants. We compared the occupancy of RNA Pol II on selected MIR genes ( 200 bp upstream of transcription initiation start site) in hyl1-2 and wild-type plants (Fig. 3B). We selected the MIR genes which were tested previously in the $c d c 5$ mutant plants (Zhang, Xie et al. 2013). The results showed that RNA Pol II distribution is affected at several MIR genes promoter regions. Our data showed an increased accumulation of RNA Pol II at the region approximately 200 base pair upstream from the transcription initiation site (TSS) for few tested MIR genes in the hyl1-2 mutant when compared to wild type plants. This observation is opposite to what was reported in $c d c 5$ mutant plants. Additionally, we examined the RNA Pol II distribution in detail on MIR393A and MIR393B genes (Fig. 3C). The higher occupancy of RNA polymerase II in these regions may suggest that, in the hyl1-2 mutant: 1) transcription of selected MIR genes is more efficient; or 2) transition from initiation to transcription elongation is deregulated. Keeping in mind our previous results where transcription of GUS reporter was downregulated in a hyl1-2 mutant when compared to wild-type plants we suggest that the accumulation of RNA Pol II on the promoter region of MIR genes in hyl1-2 is a result of RNA Pol II's inability to transition from initiation to elongation. Furthermore, we performed ChIP-seq experiments using antibodies against total RNA pol II in wild-type and hyl1-2 mutant plants for a global analysis of RNA pol II distribution along MIR genes. For the global ChIP-seq analysis we selected only MIR genes which are independent transcriptional units with determined TSS (Bielewicz, Dolata et al. 2012, Zielezinski, Dolata et al. 2015). Results clearly show increased RNA Pol II occupancy in the region of TSS as well as in the gene body of MIR genes in hyl1-2 mutant in comparison to wild-type plants (Fig. 3D). ChIP-seq data also confirmed the results obtained for MIR393A gene (Fig. S3A). Our data suggests that DRB1 acts a positive factor for RNA Pol II to transition through initiation to elongation.

\section{Knockdown of DRB1 affects gene expression of many genes.}

We were interested whether DRB1 could also affect transcription of other genes transcribed by RNA Pol II. To investigate this possibility, we analyzed publicly available transcriptomic data obtained from wild-type and hy/1-2 mutant plants. Theoretically, in hyl1-2 mutant, a generally low level of miRNAs should be accompanied by a general upregulation of miRNA targets. On the contrary, we noticed that approximately half (1531 genes) of differentially expressed genes (DEGs) (3036 genes) in hyl1-2 mutants are downregulated as compared to wild-type 
plants (Fig. 4A). We then compared these results with the transcriptomic data obtained from se-3 mutant. Our analysis showed that almost half of the DEGs are common between se-3 mutant and hyl1-2 mutant, indicating that the functions of DRB1 and SE proteins overlap (Fig. 4B). Interestingly, there is a big group of DEGs which are specifically downregulated in hyl1-2 mutant plants (769 genes). In agreement with our ChIP-seq data, RNA Pol II occupancy (on TSS and gene body) was markedly increased in genes (not limited to MIR genes) whose transcription was affected only by DRB1 (Fig. 3E). Gene ontology analysis showed that proteins encoded from these genes localized mostly in chloroplasts (Fig. 4C). Additionally, the biggest group of genes downregulated in hyl1-2 mutant is involved in biological processes of 'plastid organization' according to our gene ontology analysis (Fig. S3B). It was known that light is an important factor for DRB1 maintenance in the cell (Cho, Ben Chaabane et al. 2014). In the night DRB1 is degraded by yet unidentified protease which results in downregulation of mature microRNA level. However, our analysis suggests that DRB1 may be involved in plant response to light independent of its role in the miRNA pathway. Our data regarding the role of DRB1 outside of miRNA biogenesis is further supported by a recently published work that uncovered a novel function of DRB1 connected to skotomorphogenesis independent of its role in miRNA biogenesis (Sacnun, Crespo et al. 2019). Taken together, our data point towards a role of DRB1, outside of miRNA biogenesis, where it acts as a general transcriptional factor, though a lot more work needs to be done before we can completely elucidate the mechanism of transcriptional gene regulation by DRB1.

\section{Discussion}

The DRB1 protein plays a major role in the processing of pri-miRNAs. But it was also reported that without DRB1, in case of intron containing MIR genes both forms of pri-miRNA (before and after splicing) accumulate to high levels in Arabidopsis thaliana (Szarzynska, Sobkowiak et al. 2009). Therefore, it seems that DRB1 may have an additional function in microRNA biogenesis. It appears that the recruitment of DRB1 to the miRNA biogenesis machinery takes place at the very early stages of pri-miRNA processing, possibly before splicing occurs. For protein-coding genes, a direct connection between gene transcription and further co- and post-transcriptional processing of nascent pre-mRNAs has been shown (Bauren and Wieslander 1994, Li, Wang et al. 2019). It is known that almost all plant MIR genes are transcribed by RNA Pol II (Xie, Allen et al. 2005). In addition, similar to pre-mRNAs, primary 
transcripts of MIR genes also undergo further processing, including cap structure formation, polyadenylation, splicing and $\mathrm{m}^{6} \mathrm{~A}$ methylation. (Xie, Allen et al. 2005, Bielewicz, Kalak et al. 2013, Schwab, Speth et al. 2013, Knop, Stepien et al. 2017, Bhat, Bielewicz et al. 2019).

The results presented in this manuscript show that a GUS reporter under the control of a MIR gene promoter is expressed at a lower level when DRB1 is missing (hy/1-2 and hyl1-2/dcl1-13 background). Moreover, evaluation of the occupancy of RNA Pol II on MIR genes in hyl1-2 showed an accumulation of total RNA Pol II in the region approximately 200 base pair upstream of the transcription initiation site. This phenomenon was observed in the cases of MIR393A, MIR393B, as well as MIR159A, MIR163, MIR166A, MIR170 and MIR775A in the hyl12 mutant. While the distribution of RNA Pol II in a variety of complex genomes is correlated with gene expression, the presence of RNA Pol II at a specific locus does not necessarily indicate active expression from this locus. The higher occupancy of the RNA polymerase II at the analyzed MIR promoter regions, together with results from the GUS reporter assays, suggest that transition of transcription from initiation to elongation is impeded in the hyl1-2 mutant. This suggestion is supported by the results showing that DRB1 colocalized with total RNA pol II and also specifically and individually with RNA Pol II phosphorylated at Ser5 and Ser2. It is known that the phosphorylation status of the CTD domain of RNA Pol II is very important in transcription (Komarnitsky, Cho et al. 2000) and the interplay between kinases and phosphatases acting on RNA Pol II can modify gene expression. One of the proteins that is able to dephosphorylate the CTD of the RNA Pol II at Ser5 residue is a protein phosphatase called CPL1 (Koiwa, Hausmann et al. 2004). Similarly, it was reported that the phosphorylation status of DRB1 is also important in microRNA biogenesis (Mendoza, Du et al. 2005, Manavella, Hagmann et al. 2012, Raghuram, Sheikh et al. 2015, Su, Li et al. 2017, Yan, Wang et al. 2017, Achkar, Cho et al. 2018). It was shown that the DRB1 protein needs to be dephosphorylated for its optimal activity and this is also maintained by the CPL1 protein. Fully phosphorylated DRB1 exclusively localized in the nucleus, is not active in pri-miRNA processing, however this does not exclude it role in the transcription of MIR genes. More importantly, phosphorylation status of DRB1 could be a factor that distinguishes its role from acting in transcription and processing of pri-miRNAs. An alternative model suggests that the C-terminal region of DRB1 which displays tendencies to bind dsDNA may interact with chromatin (Bhagat, Verma et al. 2018). Our data presents new possibilities regarding DRB1's role in the plant cell but to put forward a detailed mechanism of how DRB1 affects transcription more work. 


\section{Material and methods}

\section{Plant material and growth conditions}

Arabidopsis thaliana ecotype Columbia-0 plants were used as wild-type plants, insertion mutant SALK_064863 as knockout of DRB1 (hyl1-2) and insertion mutant SAIL_44_G12 as se2. $p M I R 393 A: G U S$ and $p M I R 393 B: G U S$ reporter lines which were used in this study were described previously (Parry, Calderon-Villalobos et al. 2009). hyl1-2/dcl1-13 and pDRB1:DRB1:HA transgenic lines were obtained by floral dip transformation of hyl1-2 (Clough and Bent 1998). Genomic sequences of DCL1 and DRB1 with around $2 \mathrm{~kb}$ promoter region were cloned into pENTR-D-TOPO vector (Invitrogen). Next, site directed mutagenesis was performed to introduce $D C L 1-13$ point mutation. Finally, LR reaction was used to subcloned DCL1-13 and DRB1 sequence into pEarlyGate301 plasmid followed by Agrobacterium transformation (Earley, Haag et al. 2006).

Arabidopsis plants were grown in soil (Jiffy-7 $42 \mathrm{~mm}$; Jiffy Products International AS, Stange, Norway) or on $1 / 2$-strength MS media with $0.8 \%$ agar square plates in growth chambers (Sanyo/Panasonic, Japan) that had a 16-h day length (150-200 $\mu \mathrm{E} / \mathrm{m}^{2} \mathrm{~s}$ ), a constant temperature of $22{ }^{\circ} \mathrm{C}$ and $70 \%$ humidity. Seeds were sterilized before sowing in $10 \%$ sodium hypochlorite in $70 \%$ EtOH solution.

\section{GUS staining for reporter lines analysis:}

14 days old Arabidopsis seedlings which were grown in $1 / 2 \mathrm{MS}$ medium were incubated in staining solution containing $1 \mathrm{mM} \mathrm{X-Gluc}$ in $100 \mathrm{mM} \mathrm{Na3PO4}$ (pH 7.2), 0.1\% Triton X-100, 5 $\mathrm{mM} \mathrm{K} 3 \mathrm{Fe}(\mathrm{CN}) 6$ and $5 \mathrm{mM} \mathrm{K} 4 \mathrm{Fe}(\mathrm{CN}) 6$ for $24 \mathrm{~h}$ at $37^{\circ} \mathrm{C}$. Seedlings were then cleared in $70 \%$ ethanol for 2 days and mounted in $50 \%$ v/v glycerol before observations. After GUS staining the pictures were taken using the Leica M60 stereo microscope.

\section{RNA isolation, cDNA synthesis and qPCR.}

Total RNA from three-week-old or 14-day-old plants was isolated using the TRIzol ${ }^{\mathrm{TM}}$ reagent (Invitrogen) and a Direct-zol RNA MiniPrep Kit (Zymo Research). The RNA was then cleaned with Turbo ${ }^{\mathrm{TM}}$ DNase (Invitrogen) according to the provided protocol. Reverse transcription reaction was performed with Superscript ${ }^{\mathrm{TM}}$ III Reverse Transcriptase (Invitrogen) and oligo-dT primer. qPCR was performed with Power SYBR ${ }^{\mathrm{TM}}$ Green PCR Master Mix (Applied Biosystems) using a QuantStudio ${ }^{\mathrm{TM}} 7$ Flex Real-Time PCR System (Applied Biosystems). The 
expression levels were calculated with the $2^{-\Delta \Delta \mathrm{Ct}}$ method. The Mann-Whitney $\mathrm{U}$ test was used for statistical analyses.

\section{Chromatin Immunoprecpitation}

Chromatin immunoprecipitation was performed using nuclei isolated from crosslinked (1\% formaldehyde) 21-day old leaves, as described in (Bowler, Benvenuto et al. 2004) with minor modifications. Sonic and IP buffer were prepared as described in (Kaufmann, Muino et al. 2010). Chromatin was sonicated at $4^{\circ} \mathrm{C}$ with a Diagenode Bioruptor Plus at high intensity for $30 \mathrm{~min}$ (30 s on/30 s off) to obtain 200-300 bp DNA fragment size. Antibodies against total RNA Pol II (Abcam ab817) were used with Dynabeads Protein G (Thermo Scientific). ProteinDNA complexes were eluted from the beads as described in (Rowley, Bohmdorfer et al. 2013) and DNA was purified using a column-based method. DNA libraries were obtained using MicroPlex Library Preparation Kit (Diagenode) and sequenced on HiSeq HO 125 SE (Fasteris). Reads were trimmed to $50 \mathrm{bp}$ and aligned to the Arabidopsis genome (TAIR10) using Bowtie (wit parameters -M1 -n2) (Langmead, Trapnell et al. 2009). Duplicate reads were removed by SAMtools (Li, Handsaker et al. 2009). Remaining sequences were extended to 200bp according to ChIP fragment length. Plots of RNA Pol II distribution were made using ngs.plot software (Shen, Shao et al. 2014). Genomic coordinates of MIR genes were taken from mirEX ${ }^{2}$ data base (Zielezinski, Dolata et al. 2015).

\section{In situ immunolocalization of DRB1 and RNA polymerase II}

The double immunodetection experiments were performed according to the protocol described in (Bhat, Bielewicz et al. 2019). For HYL1 localization primary rabbit antibodies (Agrisera, AS06 136) diluted to 1:200 were used. After the double labeling assay, the slides were stained for DNA detection with Hoechst 33342 (Life Technology, USA) and mounted in ProLong Gold antifade reagent (Life Technologies).

\section{Co-immunpreciptation of partner proteins of DRB1}

For each co-immunoprecipitation (co-IP), nuclear extract was prepared like described above. Proteins were extracted from nuclear pellet by resuspending it in nuclear lysis buffer $(10 \%$ sucrose, $100 \mathrm{mM}$ Tris-HCl, pH 7.5, 5mM EDTA, 5mM EGTA, 300mM NaCl, 0.75\% Triton X-100, $0.15 \%$ sodium dodecyl sulphate (SDS), $1 \mathrm{mM}$ dithiothreitol (DTT), and $1 \times$ cOmplete $^{\mathrm{TM}}$ EDTA-free protease inhibitor (Roche)) and sonicated 2 cycle $\times 30$ second ON/ 30 second OFF using 
Bioruptor $^{\circledR}$ Plus (Diagenode). After removal of cell debris by centrifugation (5 min, 16000g, 4 ${ }^{\circ} \mathrm{C}$ ) the cleared supernatants were diluted 1 time using water containing 1 x cOmplete ${ }^{\mathrm{TM}}$ EDTAfree protease inhibitor (Roche). Protein extract was incubated overnight with anti-HA antibodies (Roche). After over-night incubation, Dynabeads with protein $\mathrm{G}$ were added and samples were incubated for $1 \mathrm{~h}$. After incubation, beads were washed 2 times with low salt buffer (20mM Tris-HCl pH 8, 2mM EDTA, 150mM NaCl, 1\% Triton X-100, 0.1\% SDS), 1 time with high salt buffer (20mM Tris-HCl pH 8, 2mM EDTA, 500mM NaCl, $1 \%$ Triton X-100, $0.1 \%$ SDS), 1 time LiCl buffer (10mM Tris-HCl pH 8, 1mM EDTA, 250mM LiCl, 1\% NP40, 0.1\% SDS, $1 \%$ sodium deoxycholate) and twice with TE (100mM Tris-HCl pH 8, 1mM EDTA). Beads containing proteins were analyzed by mass spectrometry. Control IPs were performed in Col0 using anti-HA antibodies.

Mass spectrometry analyses were performed by IBB PAS, Warsaw. Magnetic beads containing proteins were suspended in $100 \mathrm{mM}$ ammonium bicarbonate buffer, reduced using $100 \mathrm{mM}$ DTT for $30 \mathrm{~min}$ at $57^{\circ} \mathrm{C}$ and alkylated in $50 \mathrm{mM}$ iodoacetamide for $45 \mathrm{~min}$ at RT in the dark. In the next step proteins were digested overnight using $100 \mathrm{ng} / \mu \mathrm{l}$ trypsin (Promega) at $37^{\circ} \mathrm{C}$. Peptide mixtures were separated using Nano-Ultra Performance Liquid Chromatograpy coupled to Orbitrap Velos mass spectrometer (Thermo). Peptides were identified with Mascot algorithm (Matrix Science, London, UK) and searched against the TAIR10 database. The total number of MS/MS fragmentation spectra was used to quantify each protein from at least three independent biological replicates. Biological replicates consisted of plants of the same genotype grown at different dates and in different growth chambers. For the statistical analysis we compared the data from three independent experiments for pDRB1:DRB1:HA. Statistical analysis was perform with DESEq2 R-package (Love, Huber et al. 2014).

\section{Analysis of RNA-seq data}

RNA-seq data from wild type, hyl1-2 and se-3 was downloaded from published dataset under the accession number ERP001616 (Manavella, Hagmann et al. 2012). Raw reads were trimmed (first 20 nucleotides) with FASTX-Toolkit, adapters were removed using Trimmomatic and rRNA sequences where removed with Bowtie (Langmead, Trapnell et al. 2009, Bolger, Lohse et al. 2014). Clean reads were aligned to the Arabidopis TAIR10 reference genome using HISAT2 (Kim, Langmead et al. 2015). The overall alignment rate was 98-99\% for each sample. Next, prepDE.py script was used to extract count information from StringTie output and 
DESeq2 R package was used to find differentially expressed genes (Love, Huber et al. 2014). Gene ontology was performed with clusterProfiler R package (Yu, Wang et al. 2012).

\section{Acknowledgments}

This work was funded by the National Center of Sciences (NCN); Preludium grant UMO2011/03/N/NZ2/03147; Sonata grant UMO-2016/23/D/NZ1/00152 and the KNOW RNA Research Centre in Poznan (01KNOW2/2014).

\section{Conflict of Interest Statements}

The authors declare no conflict of interest.

Figure 1. DRB1 is a positive factor for transcription of MIR genes. a) Images show GUS staining of seedlings reporter lines in wild type (left), hyl1-2 (middle) and hyl1-2/dcl1-13 (right) backgrounds. b) RT- qPCR analysis of GUS transcript and pri-miRNA levels in the reporter lines in wild type and $h y / 1-2$ and $h y / 1-2 / d c / 1-13$ backgrounds. Error bars indicate SD $(n=3)$.

Figure 2. DRB1 colocalizes with RNA polymerase II in wild type plants: a) Nuclei from fixed cells where DRB1 is shown in red, RNA Pol II in green and DNA in blue. The merge column shows all 3 channels. b) Colocalization scores of DRB1 and RNA Pol Il calculated by three different approaches (Pearson, Spearman and LiQ).

Figure 3. DRB1 interacts with transcriptional factors and is important for proper distribution of RNA polymerase II along MIR genes: a) The DRB1 interactome determined by co-immunoprecipitation followed by Mass Spectrometry b) The occupancy of total RNA Pol Il at promoter regions on different MIR genes ( 200 bp upstream of TSS). c) The occupancy of total RNA Pol II at the MIR393A or MIR393B loci using ChIP followed by qPCR. The region marked with an asterisk represents the statistically significant enrichment of RNA Pol II in hyl1-2 as compared to wild-type plants. Schematic gene structure is shown, and red lines show the amplified regions. Error bars represent the SD of three independent biological 
replicates.

Figure 4. Downregulation of RNA Pol II transcripts in DRB1 mutant. a) MAplot showing the

DEGs in hyl1-2 mutant as compared to wild type. Red color indicates the statistically

significant genes b) Venn diagram showing the overlap of DEGs between hyl1-2 and se-3

mutants. c) Gene ontology analysis performed on 769 genes which are downregulated in

Figure S1. HYL1 stimulates transcription from MIR genes. Analysis of hyl1-2/dcl1-13

transgenic lines. RT-qPCR analysis of levels of 6 pri-miRNAs in wild type, hyl1-2 and four

independent $h y / 1-2 / d c / 1-13$ transgenic lines (left). Error bars indicate SD $(n=3)$. Northern blot

transgenic lines (right). U6 serves as a positive control for northern blot hybridization

Figure S2. DRB1 colocalizes with RNA polymerase II in se-2 mutant plants: a) Nuclei from

three different approaches (Pearson, Spearman and LiQ). 
Fig. 1

A

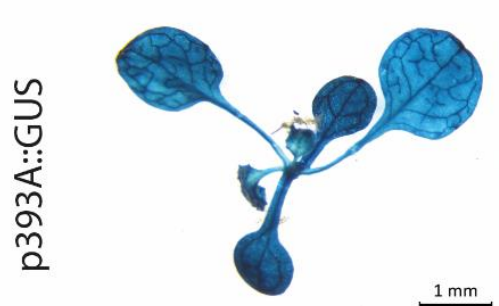

WT

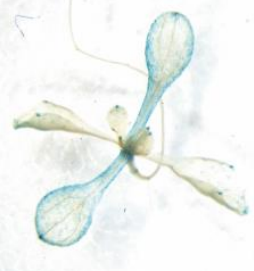

hyll-2

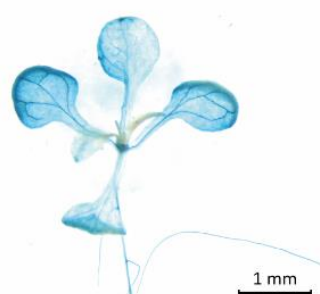

hyll-2/dcl1-13

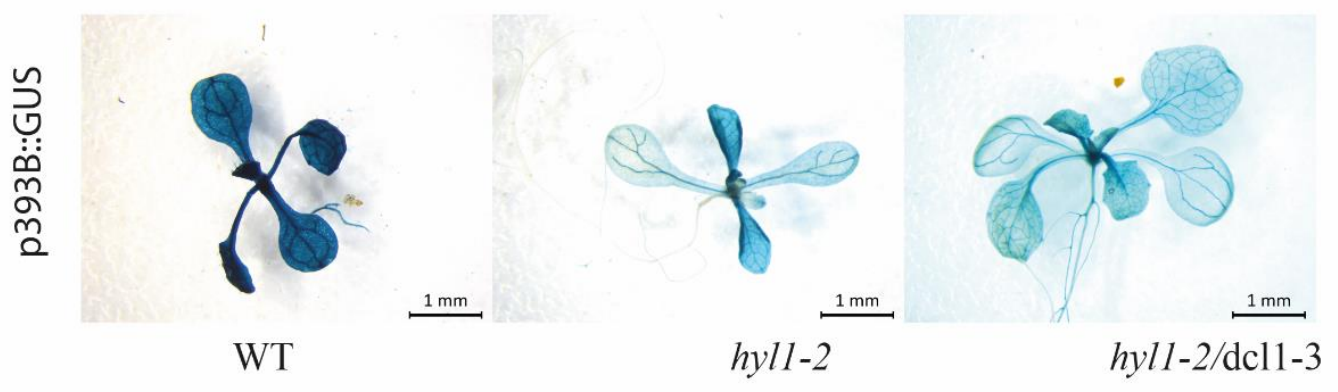

B
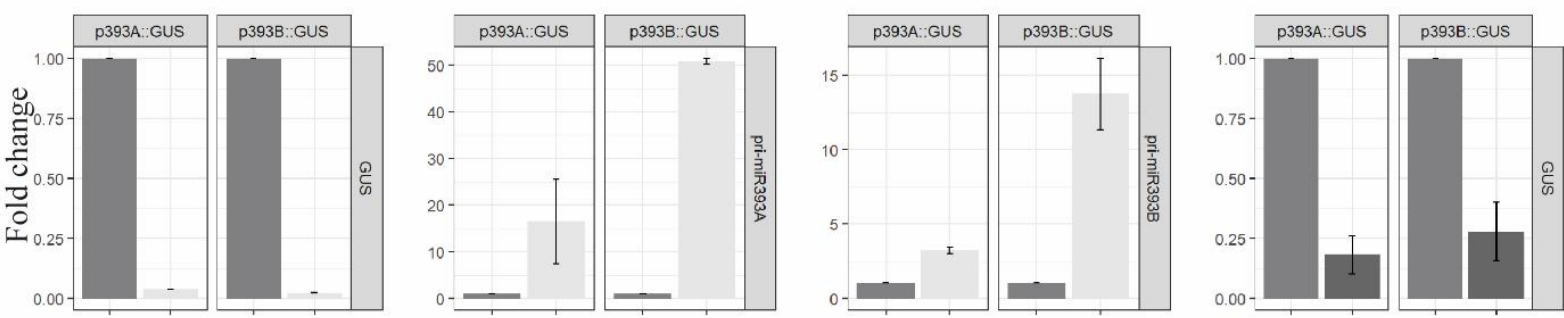

wt $\quad$ hy11-2

wt hyl1-2

wt $\quad$ hyl1-2

wt hyl1-2/dc1-13 
bioRxiv preprint doi: https://doi.org/10.1101/2019.12.30.890665; this version posted December 30, 2019. The copyright holder for this preprint (which was not certified by peer review) is the author/funder, who has granted bioRxiv a license to display the preprint in perpetuity. It is made available under aCC-BY-NC-ND 4.0 International license.

Fig. 2

A
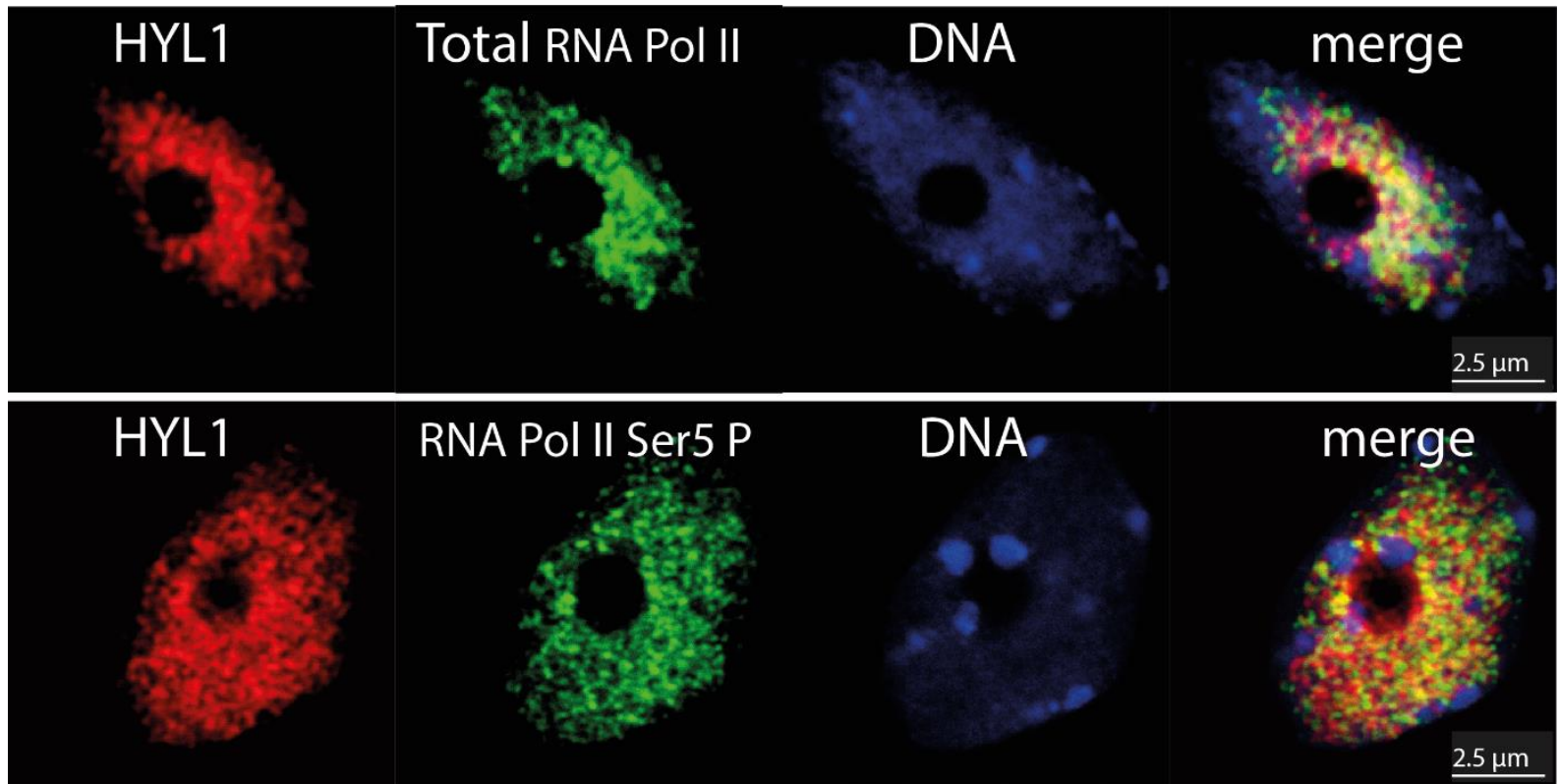

$\underline{2.5 \mu \mathrm{m}}$

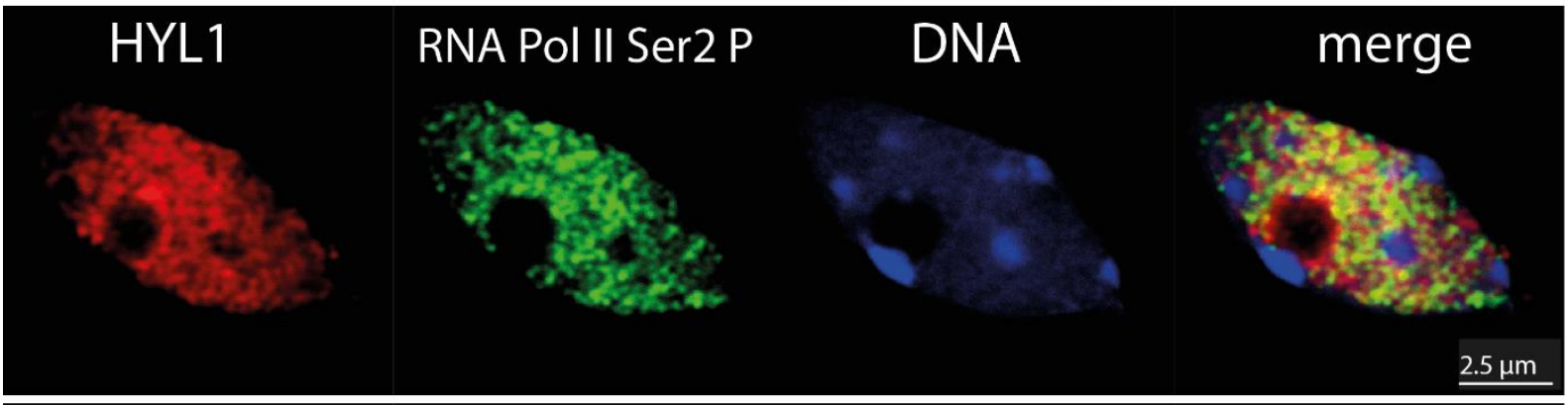

HYL1

RNA Pol II Thr4 P

DNA

merge

B

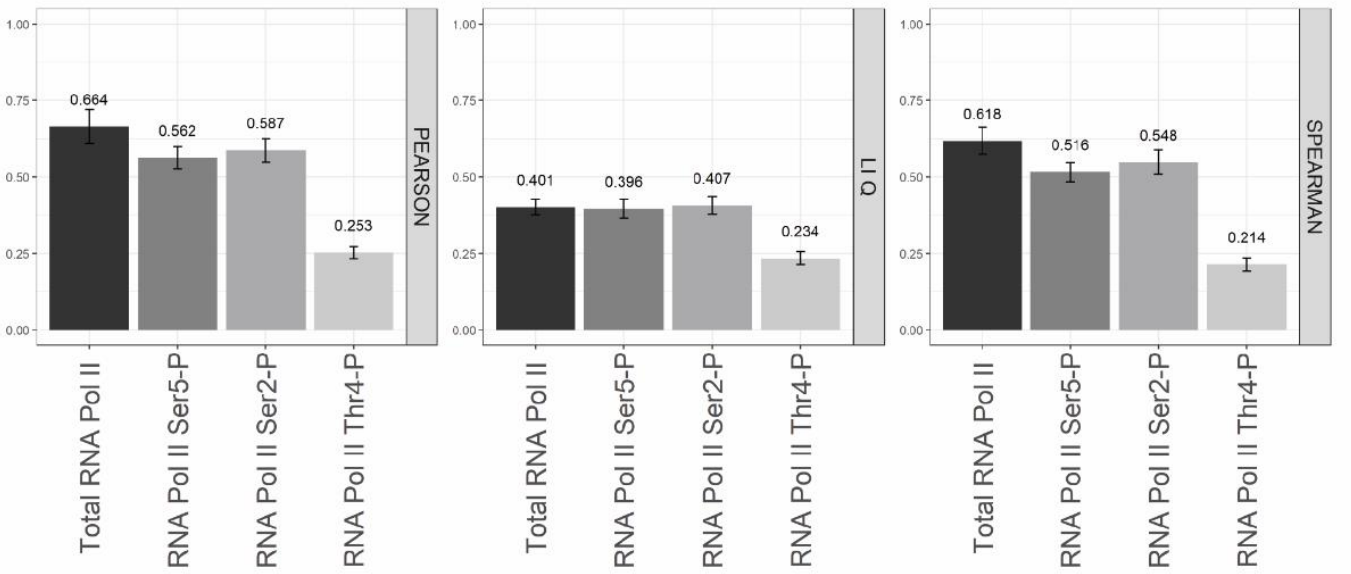


bioRxiv preprint doi: https://doi.org/10.1101/2019.12 30.890665; this version posted December 30,2019. The copyright holder for this preprint (which was not certified by peer review) is the author/funder, who has granted bioRxiv a license to display the preprint in perpetuity. It is made available under aCC-BY-NC-ND 4.0 International license.

Fig. 3

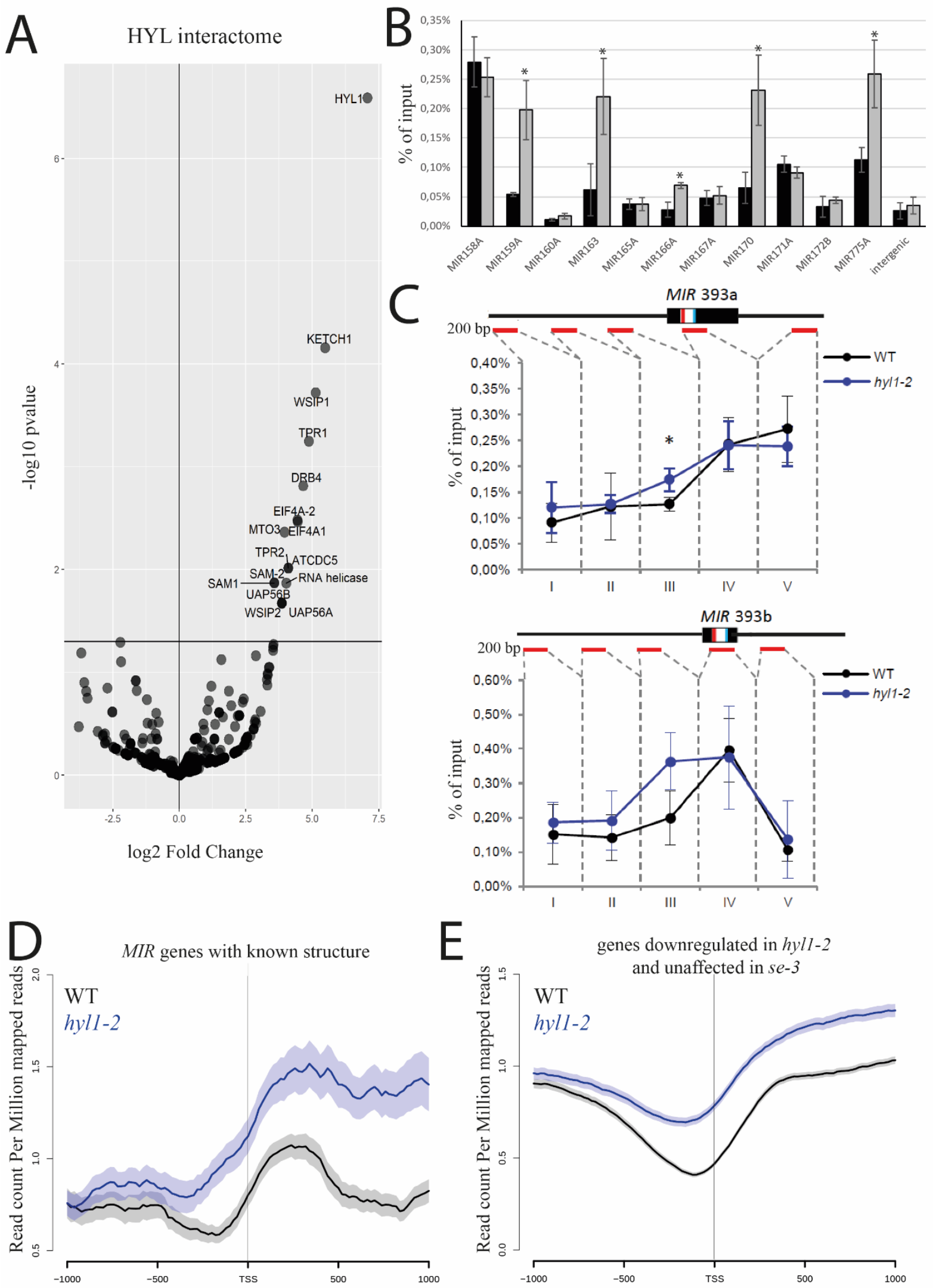


bioRxiv preprint doi: https://doi.org/10.1101/2019.12 30.890665; this version posted December 30,2019 . The copyright holder for this preprint (which was not certified by peer review) is the author/funder, who has granted bioRxiv a license to display the preprint in perpetuity. It is made available under aCC-BY-NC-ND 4.0 International license.

Fig. 4

A

Col0 vs hyl1-2 (bonferroni $<0.001)$

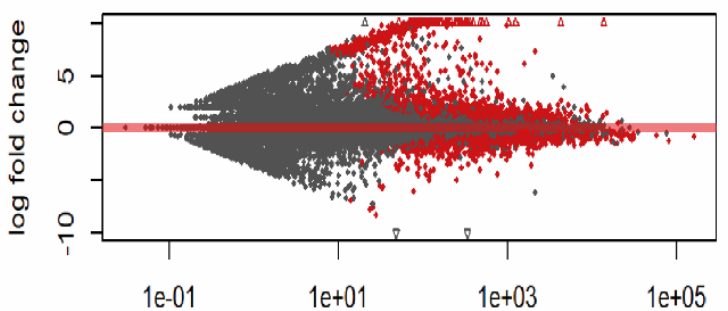

B

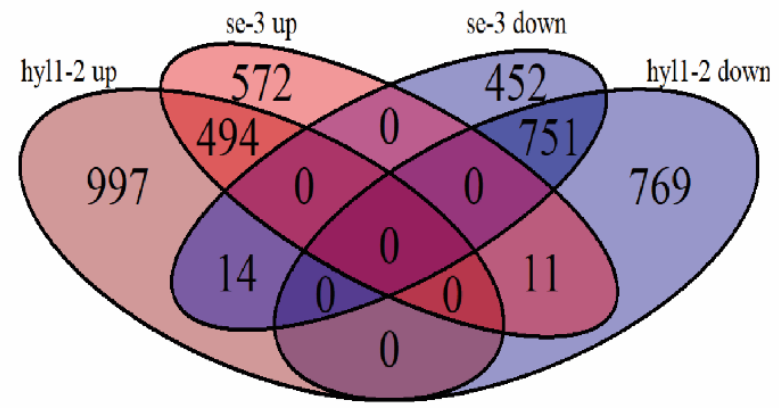

GO Cellular Compartment (769 genes)

thylakoid part

thylakoid membrane

thylakoid

ribosome

ribonucleoprotein complex

plastid thylakoid membrane

$$
\text { plastid }
$$
thylakoid

photosynthetic membrane

chloroplast

thylakoid

membrane

chloroplast thylakoid
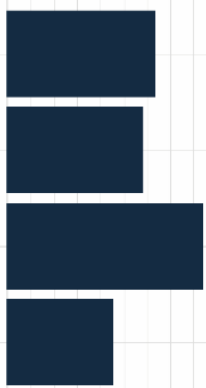

p.adjust
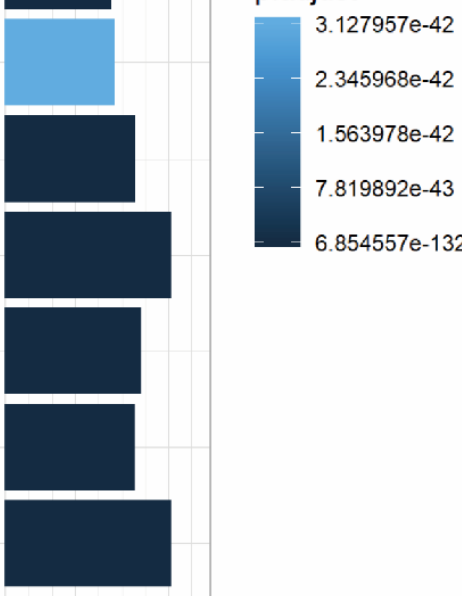

- 오운 운

Count 
bioRxiv preprint doi: https://doi org/10.1101/2019.12 30.890665; this version posted December 30, 2019. The copyright holder for this preprint (which was not certified by peer review) is the author/funder, who has granted bioRxiv a license to display the preprint in perpetuity. It is made available under aCC-BY-NC-ND 4.0 International license.

Fig. S1

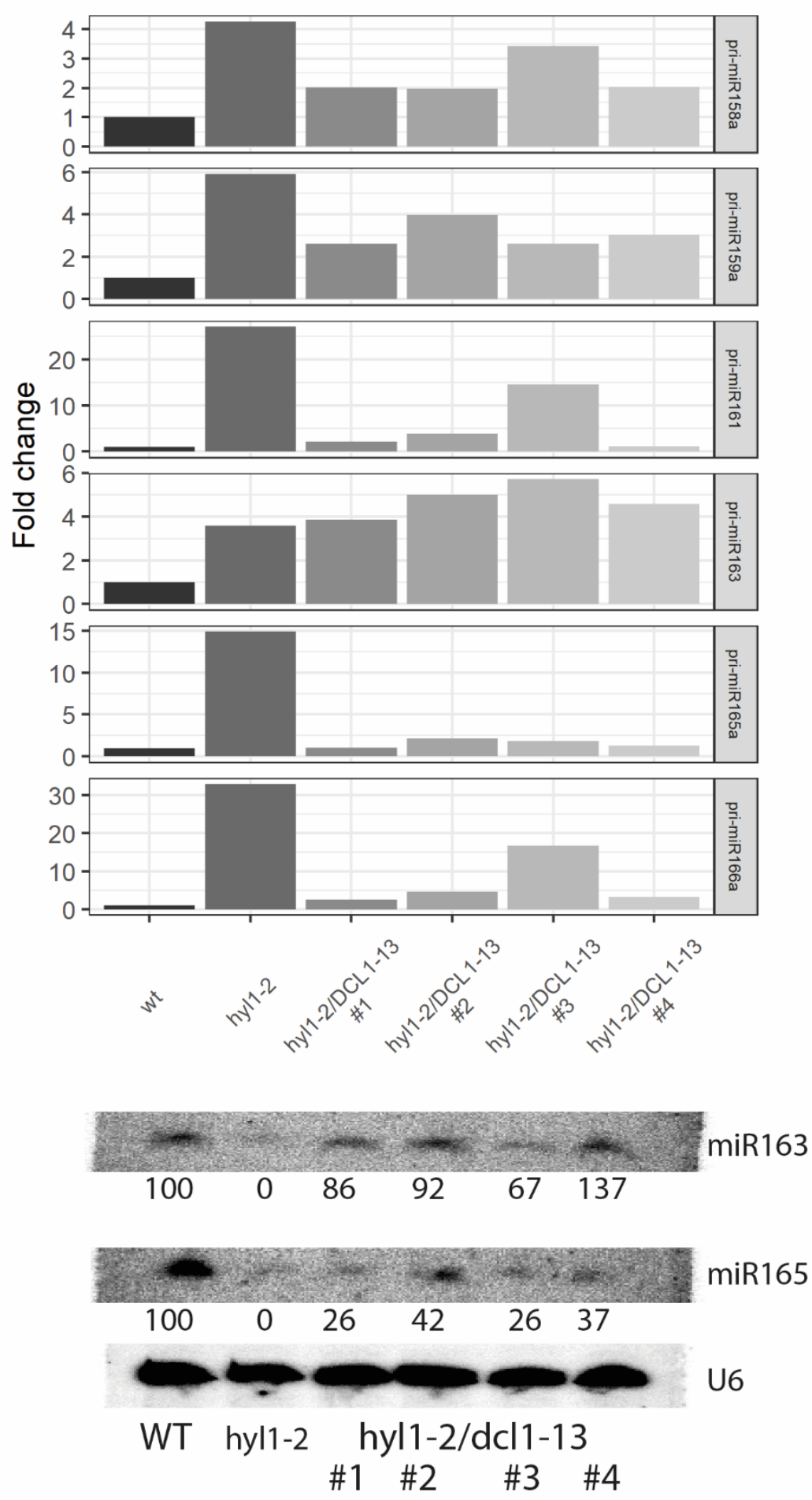


bioRxiv preprint doi: https://doi.org/10.1101/2019.12.30.890665; this version posted December 30,2019. The copyright holder for this preprint (which was not certified by peer review) is the author/funder, who has granted bioRxiv a license to display the preprint in perpetuity. It is made available under aCC-BY-NC-ND 4.0 International license.

Fig. S2

A

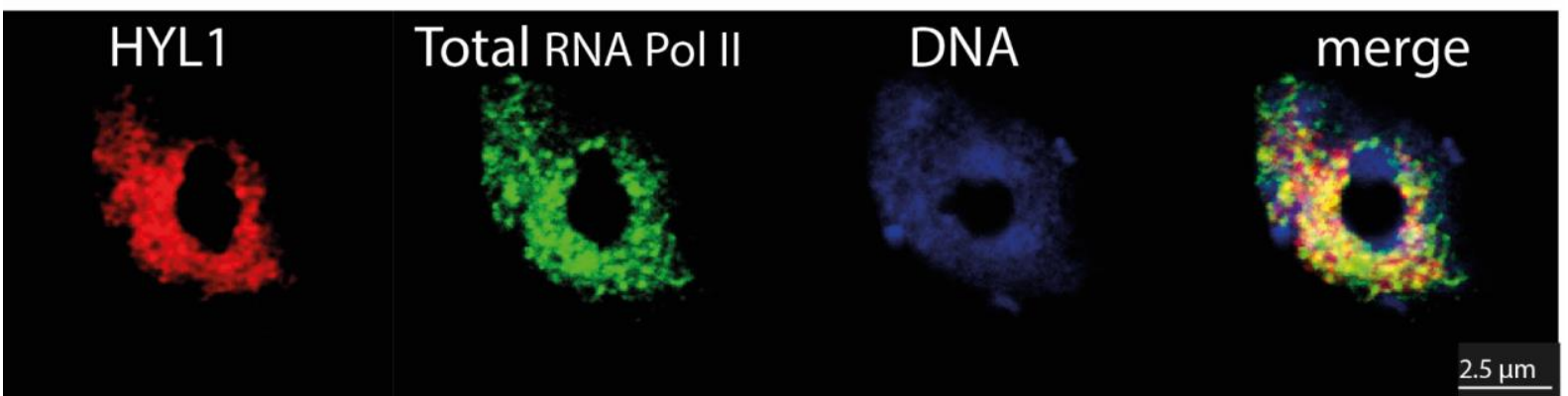

HYL1

RNA Pol II Ser5 P

DNA

merge

$2.5 \mu \mathrm{m}$
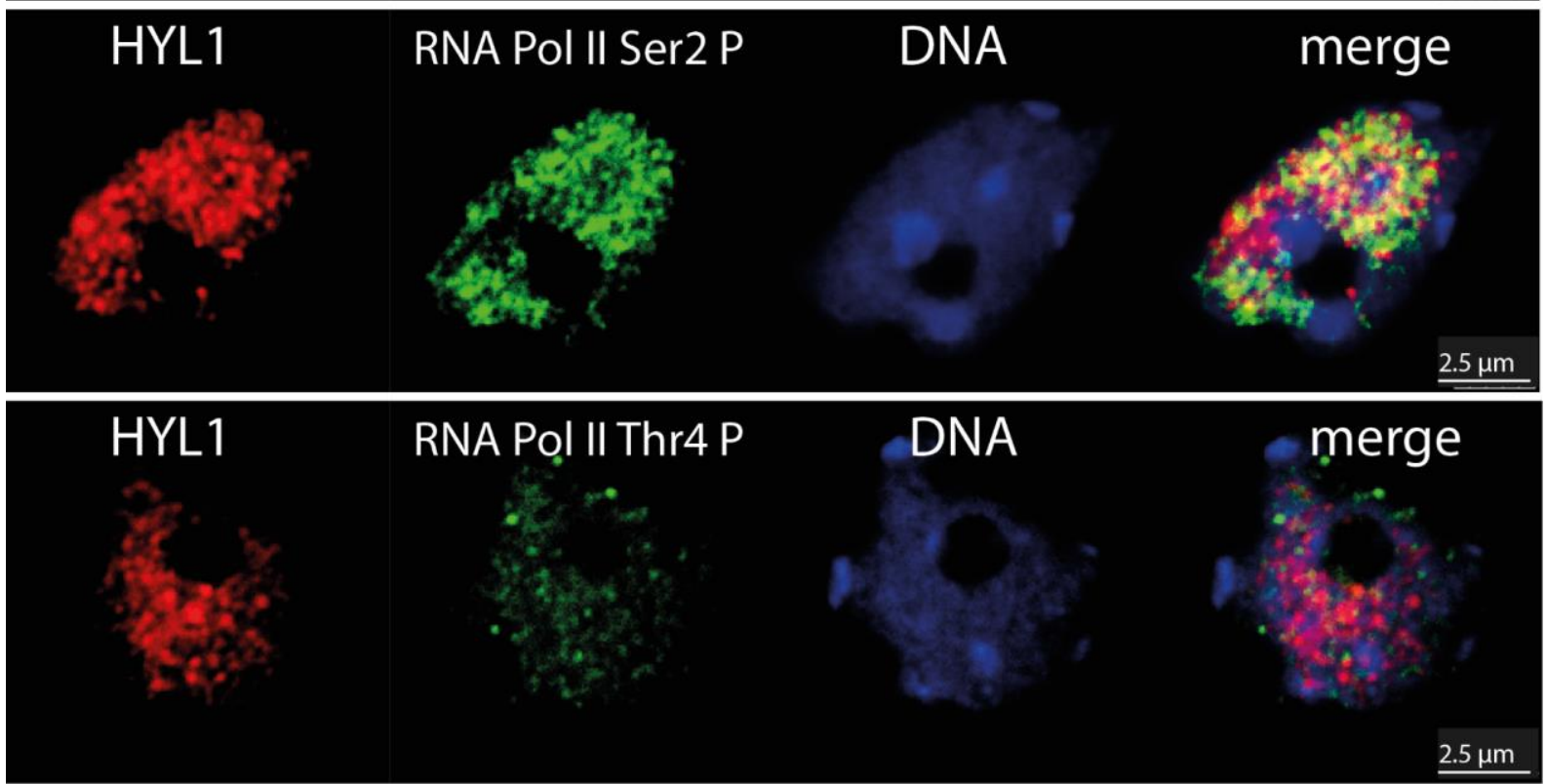

B

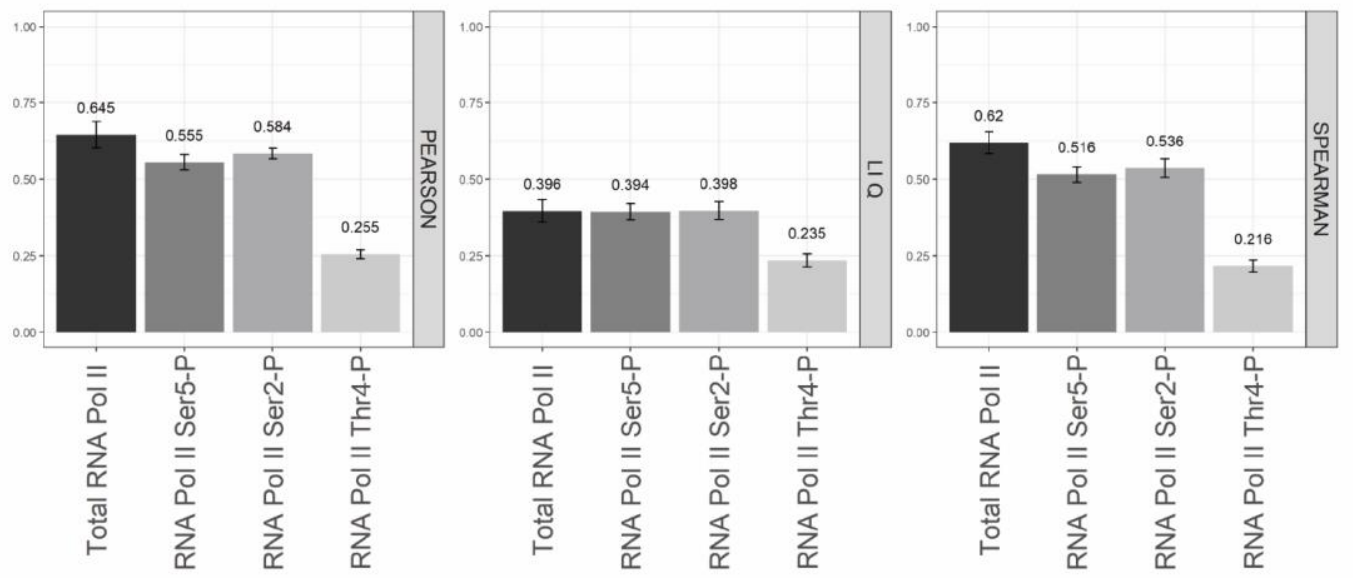


Fig. S3

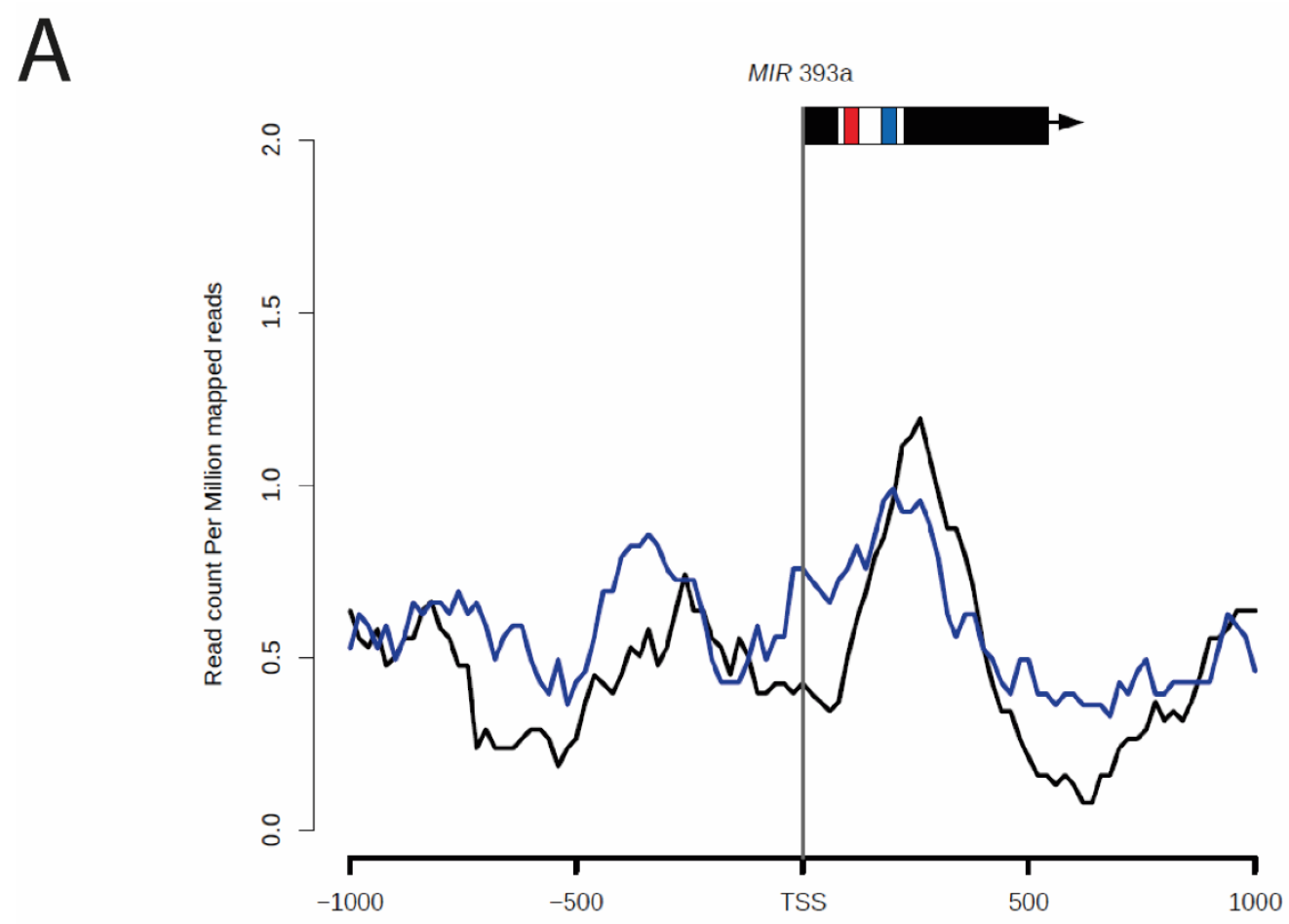

B

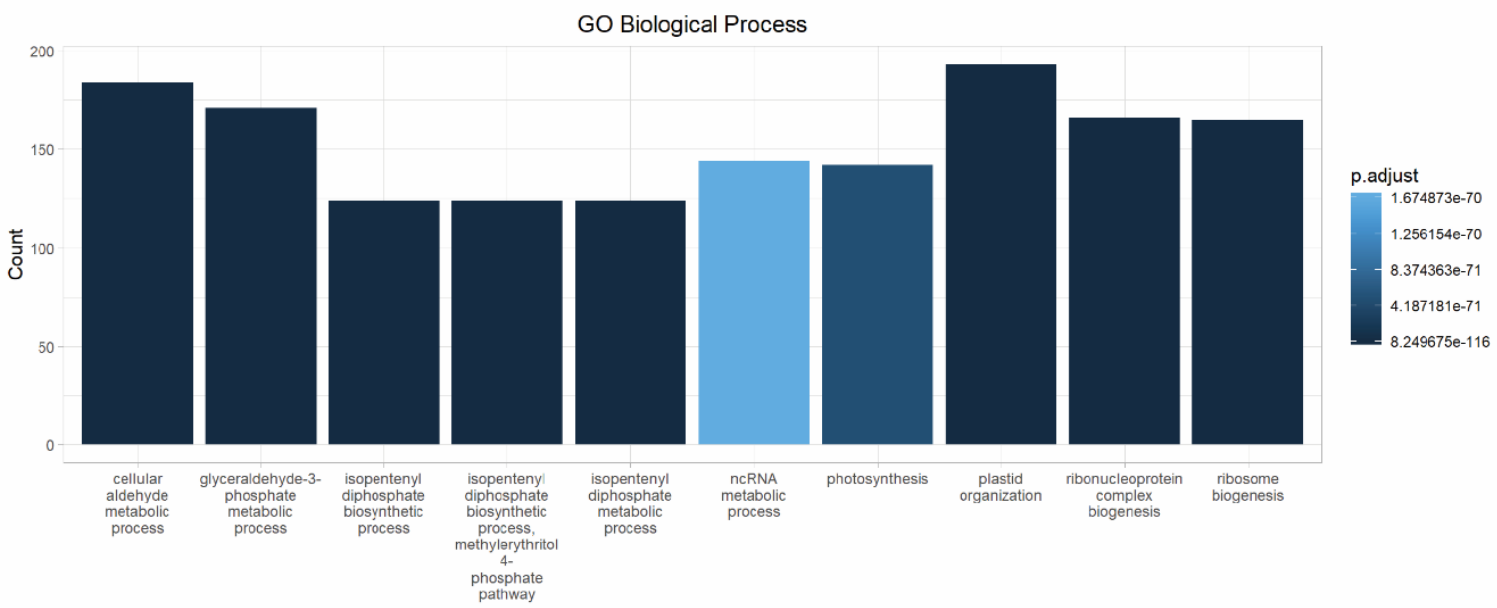

\section{References}

Achkar, N. P., S. K. Cho, C. Poulsen, A. L. Arce, D. A. Re, A. J. Giudicatti, E. Karayekov, M. Y. Ryu, S. W. Choi, J. Harholt, J. J. Casal, S. W. Yang and P. A. Manavella (2018). "A Quick HYL1-Dependent Reactivation of MicroRNA Production Is Required for a Proper Developmental Response after Extended Periods of Light Deprivation." Developmental Cell 46(2): 236-247.e236. expression regulation in a wide range of abiotic stress responses." Front Plant Sci 6: 410. 297. 
Bauren, G. and L. Wieslander (1994). "Splicing of Balbiani ring 1 gene pre-mRNA occurs simultaneously with transcription." Cell 76(1): 183-192. Bhagat, P. K., D. Verma, R. Badmi and A. K. Sinha (2018). "Dynamic regulation of HYL1 provides new insights into its multifaceted role in Arabidopsis " bioRxiv. Bhat, S. S., D. Bielewicz, N. Grzelak, T. Gulanicz, Z. Bodi, L. Szewc, M. Bajczyk, J. Dolata, D. J. Smolinski, R. G. Fray, A. Jarmolowski and Z. Szweykowska-Kulinska (2019). "mRNA adenosine methylase (MTA) deposits m6A on pri-miRNAs to modulate miRNA biogenesis in Arabidopsis thaliana." bioRxiv. Bielewicz, D., J. Dolata, A. Zielezinski, S. Alaba, B. Szarzynska, M. W. Szczesniak, A. Jarmolowski, Z. Szweykowska-Kulinska and W. M. Karlowski (2012). "mirEX: a platform for comparative exploration of plant pri-miRNA expression data." Nucleic Acids Res 40(Database issue): D191-197. Bielewicz, D., M. Kalak, M. Kalyna, D. Windels, A. Barta, F. Vazquez, Z. Szweykowska-Kulinska and A. Jarmolowski (2013). "Introns of plant pri-miRNAs enhance miRNA biogenesis." EMBO Rep 14(7): 622628.

Bolger, A. M., M. Lohse and B. Usadel (2014). "Trimmomatic: a flexible trimmer for Illumina sequence data." Bioinformatics 30(15): 2114-2120.

Bologna, N. G., J. L. Mateos, E. G. Bresso and J. F. Palatnik (2009). "A loop-to-base processing mechanism underlies the biogenesis of plant microRNAs miR319 and miR159." EMBO J 28(23): 36463656.

Bowler, C., G. Benvenuto, P. Laflamme, D. Molino, A. V. Probst, M. Tariq and J. Paszkowski (2004). "Chromatin techniques for plant cells." Plant J 39(5): 776-789.

Burdisso, P., F. Milia, A. L. Schapire, N. G. Bologna, J. F. Palatnik and R. M. Rasia (2014). "Structural determinants of Arabidopsis thaliana Hyponastic leaves 1 function in vivo." PLoS One 9(11): e113243. Chen, X. (2004). "A microRNA as a translational repressor of APETALA2 in Arabidopsis flower development." Science 303(5666): 2022-2025.

Chendrimada, T. P., R. I. Gregory, E. Kumaraswamy, J. Norman, N. Cooch, K. Nishikura and R. Shiekhattar (2005). "TRBP recruits the Dicer complex to Ago2 for microRNA processing and gene silencing." Nature 436(7051): 740-744.

Cho, S. K., S. Ben Chaabane, P. Shah, C. P. Poulsen and S. W. Yang (2014). "COP1 E3 ligase protects HYL1 to retain microRNA biogenesis." Nature Communications 5: 5867.

Clough, S. J. and A. F. Bent (1998). "Floral dip: a simplified method for Agrobacterium-mediated transformation of Arabidopsis thaliana." Plant J 16(6): 735-743.

Dolata, J., M. Taube, M. Bajczyk, A. Jarmolowski, Z. Szweykowska-Kulinska and D. Bielewicz (2018). "Regulation of Plant Microprocessor Function in Shaping microRNA Landscape." Front Plant Sci 9: 753.

Dong, Z., M. H. Han and N. Fedoroff (2008). "The RNA-binding proteins HYL1 and SE promote accurate in vitro processing of pri-miRNA by DCL1." Proc Natl Acad Sci U S A 105(29): 9970-9975. Earley, K. W., J. R. Haag, O. Pontes, K. Opper, T. Juehne, K. Song and C. S. Pikaard (2006). "Gatewaycompatible vectors for plant functional genomics and proteomics." Plant J 45(4): 616-629.

Fang, X., Y. Cui, Y. Li and Y. Qi (2015). "Transcription and processing of primary microRNAs are coupled by Elongator complex in Arabidopsis." Nat Plants 1: 15075.

Fang, Y. and D. L. Spector (2007). "Identification of nuclear dicing bodies containing proteins for microRNA biogenesis in living Arabidopsis plants." Curr Biol 17(9): 818-823.

Gregory, R. I., K. P. Yan, G. Amuthan, T. Chendrimada, B. Doratotaj, N. Cooch and R. Shiekhattar (2004). "The Microprocessor complex mediates the genesis of microRNAs." Nature 432(7014): 235240.

Gromak, N., M. Dienstbier, S. Macias, M. Plass, E. Eyras, J. F. Caceres and N. J. Proudfoot (2013). "Drosha regulates gene expression independently of RNA cleavage function." Cell Rep 5(6): 14991510.

Haase, A. D., L. Jaskiewicz, H. Zhang, S. Laine, R. Sack, A. Gatignol and W. Filipowicz (2005). "TRBP, a regulator of cellular PKR and HIV-1 virus expression, interacts with Dicer and functions in RNA silencing." EMBO Rep 6(10): 961-967. 
Han, J., Y. Lee, K. H. Yeom, Y. K. Kim, H. Jin and V. N. Kim (2004). "The Drosha-DGCR8 complex in primary microRNA processing." Genes Dev 18(24): 3016-3027.

Hintermair, C., M. Heidemann, F. Koch, N. Descostes, M. Gut, I. Gut, R. Fenouil, P. Ferrier, A. Flatley, E. Kremmer, R. D. Chapman, J. C. Andrau and D. Eick (2012). "Threonine-4 of mammalian RNA polymerase II CTD is targeted by Polo-like kinase 3 and required for transcriptional elongation." EMBO J 31(12): 2784-2797.

Kaufmann, K., J. M. Muino, M. Osteras, L. Farinelli, P. Krajewski and G. C. Angenent (2010). "Chromatin immunoprecipitation (ChIP) of plant transcription factors followed by sequencing (ChIPSEQ) or hybridization to whole genome arrays (ChIP-CHIP)." Nat Protoc 5(3): 457-472. Kim, D., B. Langmead and S. L. Salzberg (2015). "HISAT: a fast spliced aligner with low memory requirements." Nat Methods 12(4): 357-360.

Knop, K., A. Stepien, M. Barciszewska-Pacak, M. Taube, D. Bielewicz, M. Michalak, J. W. Borst, A. Jarmolowski and Z. Szweykowska-Kulinska (2017). "Active 5' splice sites regulate the biogenesis efficiency of Arabidopsis microRNAs derived from intron-containing genes." Nucleic Acids Res 45(5): 2757-2775.

Koiwa, H., S. Hausmann, W. Y. Bang, A. Ueda, N. Kondo, A. Hiraguri, T. Fukuhara, J. D. Bahk, D. J. Yun, R. A. Bressan, P. M. Hasegawa and S. Shuman (2004). "Arabidopsis C-terminal domain phosphataselike 1 and 2 are essential Ser-5-specific C-terminal domain phosphatases." Proc Natl Acad Sci U SA 101(40): 14539-14544.

Komarnitsky, P., E. J. Cho and S. Buratowski (2000). "Different phosphorylated forms of RNA polymerase II and associated mRNA processing factors during transcription." Genes Dev 14(19): 2452-2460.

Kruszka, K., M. Pieczynski, D. Windels, D. Bielewicz, A. Jarmolowski, Z. Szweykowska-Kulinska and F. Vazquez (2012). "Role of microRNAs and other sRNAs of plants in their changing environments." J Plant Physiol 169(16): 1664-1672.

Kurihara, Y., Y. Takashi and Y. Watanabe (2006). "The interaction between DCL1 and HYL1 is important for efficient and precise processing of pri-miRNA in plant microRNA biogenesis." RNA 12(2): 206-212.

Kurihara, Y. and Y. Watanabe (2004). "Arabidopsis micro-RNA biogenesis through Dicer-like 1 protein functions." Proc Natl Acad Sci U S A 101(34): 12753-12758.

Langmead, B., C. Trapnell, M. Pop and S. L. Salzberg (2009). "Ultrafast and memory-efficient alignment of short DNA sequences to the human genome." Genome Biol 10(3): R25. Laubinger, S., T. Sachsenberg, G. Zeller, W. Busch, J. U. Lohmann, G. Ratsch and D. Weigel (2008). "Dual roles of the nuclear cap-binding complex and SERRATE in pre-mRNA splicing and microRNA processing in Arabidopsis thaliana." Proc Natl Acad Sci U S A 105(25): 8795-8800.

Li, H., B. Handsaker, A. Wysoker, T. Fennell, J. Ruan, N. Homer, G. Marth, G. Abecasis, R. Durbin and S. Genome Project Data Processing (2009). "The Sequence Alignment/Map format and SAMtools." Bioinformatics 25(16): 2078-2079.

Li, S., Y. Wang, Y. Zhao, X. Zhao, X. Chen and Z. Gong (2019). "Global co-transcriptional splicing in Arabidopsis and the correlation with splicing regulation in mature RNAs." Mol Plant. Love, M. I., W. Huber and S. Anders (2014). "Moderated estimation of fold change and dispersion for RNA-seq data with DESeq2." Genome Biol 15(12): 550.

Lu, C. and N. Fedoroff (2000). "A mutation in the Arabidopsis HYL1 gene encoding a dsRNA binding protein affects responses to abscisic acid, auxin, and cytokinin." Plant Cell 12(12): 2351-2366. Manavella, P. A., J. Hagmann, F. Ott, S. Laubinger, M. Franz, B. Macek and D. Weigel (2012). "Fastforward genetics identifies plant CPL phosphatases as regulators of miRNA processing factor HYL1." Cell 151(4): 859-870.

Mendoza, M. C., F. Du, N. Iranfar, N. Tang, H. Ma, W. F. Loomis and R. A. Firtel (2005). "Loss of SMEK, a novel, conserved protein, suppresses MEK1 null cell polarity, chemotaxis, and gene expression defects." Mol Cell Biol 25(17): 7839-7853. 
Nojima, T., K. Rebelo, T. Gomes, A. R. Grosso, N. J. Proudfoot and M. Carmo-Fonseca (2018). "RNA Polymerase II Phosphorylated on CTD Serine 5 Interacts with the Spliceosome during Cotranscriptional Splicing." Mol Cell 72(2): 369-379 e364.

Palatnik, J. F., E. Allen, X. Wu, C. Schommer, R. Schwab, J. C. Carrington and D. Weigel (2003). "Control of leaf morphogenesis by microRNAs." Nature 425(6955): 257-263.

Park, W., J. Li, R. Song, J. Messing and X. Chen (2002). "CARPEL FACTORY, a Dicer homolog, and HEN1, a novel protein, act in microRNA metabolism in Arabidopsis thaliana." Curr Biol 12(17): 1484-1495. Paroo, Z., X. Ye, S. Chen and Q. Liu (2009). "Phosphorylation of the human microRNA-generating complex mediates MAPK/Erk signaling." Cell 139(1): 112-122.

Parry, G., L. I. Calderon-Villalobos, M. Prigge, B. Peret, S. Dharmasiri, H. Itoh, E. Lechner, W. M. Gray, M. Bennett and M. Estelle (2009). "Complex regulation of the TIR1/AFB family of auxin receptors." Proc Natl Acad Sci U S A 106(52): 22540-22545.

Raczynska, K. D., A. Stepien, D. Kierzkowski, M. Kalak, M. Bajczyk, J. McNicol, C. G. Simpson, Z. Szweykowska-Kulinska, J. W. Brown and A. Jarmolowski (2014). "The SERRATE protein is involved in alternative splicing in Arabidopsis thaliana." Nucleic Acids Res 42(2): 1224-1244.

Raghuram, B., A. H. Sheikh, Y. Rustagi and A. K. Sinha (2015). "MicroRNA biogenesis factor DRB1 is a phosphorylation target of mitogen activated protein kinase MPK3 in both rice and Arabidopsis." $\underline{\text { FEBS }}$ J 282(3): 521-536.

Reinhart, B. J., E. G. Weinstein, M. W. Rhoades, B. Bartel and D. P. Bartel (2002). "MicroRNAs in plants." Genes Dev 16(13): 1616-1626.

Rowley, M. J., G. Bohmdorfer and A. T. Wierzbicki (2013). "Analysis of long non-coding RNAs produced by a specialized RNA polymerase in Arabidopsis thaliana." Methods 63(2): 160-169. Sacnun, J. M., R. Crespo, J. Palatnik, R. Rasia and N. González-Schain (2019). "Dual function of HYPONASTIC LEAVES 1 during early skotomorphogenic growth

3 in Arabidopsis." bioRxiv. Schwab, R., C. Speth, S. Laubinger and O. Voinnet (2013). "Enhanced microRNA accumulation through stemloop-adjacent introns." EMBO Rep 14(7): 615-621.

Shen, L., N. Shao, X. Liu and E. Nestler (2014). "ngs.plot: Quick mining and visualization of nextgeneration sequencing data by integrating genomic databases." BMC Genomics 15: 284. Speth, C., E. X. Szabo, C. Martinho, S. Collani, S. Zur Oven-Krockhaus, S. Richter, I. Droste-Borel, B. Macek, Y. D. Stierhof, M. Schmid, C. Liu and S. Laubinger (2018). "Arabidopsis RNA processing factor SERRATE regulates the transcription of intronless genes." Elife 7.

Su, C., Z. Li, J. Cheng, L. Li, S. Zhong, L. Liu, Y. Zheng and B. Zheng (2017). "The Protein Phosphatase 4 and SMEK1 Complex Dephosphorylates HYL1 to Promote miRNA Biogenesis by Antagonizing the MAPK Cascade in Arabidopsis." Dev Cell 41(5): 527-539 e525.

Szarzynska, B., L. Sobkowiak, B. D. Pant, S. Balazadeh, W. R. Scheible, B. Mueller-Roeber, A. Jarmolowski and Z. Szweykowska-Kulinska (2009). "Gene structures and processing of Arabidopsis thaliana HYL1-dependent pri-miRNAs." Nucleic Acids Res 37(9): 3083-3093.

Tagami, Y., H. Motose and Y. Watanabe (2009). "A dominant mutation in DCL1 suppresses the hyl1 mutant phenotype by promoting the processing of miRNA." RNA 15(3): 450-458.

Vazquez, F., V. Gasciolli, P. Crete and H. Vaucheret (2004). "The nuclear dsRNA binding protein HYL1 is required for microRNA accumulation and plant development, but not posttranscriptional transgene silencing." Curr Biol 14(4): 346-351.

Xie, Z., E. Allen, N. Fahlgren, A. Calamar, S. A. Givan and J. C. Carrington (2005). "Expression of Arabidopsis MIRNA genes." Plant Physiol 138(4): 2145-2154.

Yan, J., P. Wang, B. Wang, C. C. Hsu, K. Tang, H. Zhang, Y. J. Hou, Y. Zhao, Q. Wang, C. Zhao, X. Zhu, W. A. Tao, J. Li and J. K. Zhu (2017). "The SnRK2 kinases modulate miRNA accumulation in Arabidopsis." PLoS Genet 13(4): e1006753.

Yang, L., Z. Liu, F. Lu, A. Dong and H. Huang (2006). "SERRATE is a novel nuclear regulator in primary microRNA processing in Arabidopsis." Plant J 47(6): 841-850. 
544 Yang, S. W., H. Y. Chen, J. Yang, S. Machida, N. H. Chua and Y. A. Yuan (2010). "Structure of 545 Arabidopsis HYPONASTIC LEAVES1 and its molecular implications for miRNA processing." Structure 546 18(5): 594-605.

547 Yang, X., W. Ren, Q. Zhao, P. Zhang, F. Wu and Y. He (2014). "Homodimerization of HYL1 ensures the 548 correct selection of cleavage sites in primary miRNA." Nucleic Acids Res 42(19): 12224-12236.

549 Yu, G., L. G. Wang, Y. Han and Q. Y. He (2012). "clusterProfiler: an R package for comparing biological 550 themes among gene clusters." OMICS 16(5): 284-287.

551 Zhang, S., M. Xie, G. Ren and B. Yu (2013). "CDC5, a DNA binding protein, positively regulates posttranscriptional processing and/or transcription of primary microRNA transcripts." Proc Natl Acad 553 SciU S A 110(43): 17588-17593.

554 Zhang, Z., X. Guo, C. Ge, Z. Ma, M. Jiang, T. Li, H. Koiwa, S. W. Yang and X. Zhang (2017). "KETCH1 imports HYL1 to nucleus for miRNA biogenesis in Arabidopsis." Proc Natl Acad Sci U S A 114(15): 556 4011-4016. Zielezinski, A., J. Dolata, S. Alaba, K. Kruszka, A. Pacak, A. Swida-Barteczka, K. Knop, A. Stepien, D. Bielewicz, H. Pietrykowska, I. Sierocka, L. Sobkowiak, A. Lakomiak, A. Jarmolowski, Z. SzweykowskaKulinska and W. M. Karlowski (2015). "mirEX 2.0 - an integrated environment for expression profiling of plant microRNAs." BMC Plant Biol 15: 144. 